\title{
Previous Stress Attenuates the Susceptibility to Midazolam's Disruptive Effect on Fear Memory Reconsolidation: Influence of Pre-Reactivation D-Cycloserine Administration
}

\author{
Silvia Gabriela Bustos', Marcelo Giachero', Héctor Maldonado² and Víctor Alejandro Molina*,' \\ 'Departamento de Farmacología, IFEC-CONICET, Facultad de Ciencias Químicas, Universidad Nacional de Córdoba, Haya de la Torre y Medina \\ Allende, Ciudad Universitaria, Córdoba, Argentina; ${ }^{2}$ Laboratorio de Neurobiología de la Memoria, Departamento de Fisiología y Biología \\ Molecular, IFIBYNE-CONICET, Pabellón II, Facultad de Ciencias Exactas y Naturales (CI 428EHA), Universidad de Buenos Aires, Buenos Aires, \\ Argentina
}

It is well known that, under certain boundary conditions, the retrieval of a stable consolidated memory results into a labile one. During this unstable phase, memory can be vulnerable to interference by a number of pharmacological agents, including benzodiazepines. One of the goals of this study was to evaluate the vulnerability to midazolam (MDZ) after reactivation of recent and remote contextual fear memories in animals that experienced a stressful situation before learning. Animals were subjected to a restraint session and trained in a contextual fear paradigm the following day; consolidated memories were reactivated at different times after learning and different MDZ doses $(1.5,3.0 \mathrm{mg} / \mathrm{kg}$ ) were administered to rats after reactivation. Our results show that MDZ did not affect memory reconsolidation in older-than-one-day memories of stressed animals, even after the administration of a higher MDZ dose and a longer reactivation session (5 min). In contrast, MDZ was effective in blocking reconsolidation at all memory ages in unstressed animals. In addition, the current research investigated whether activating NMDA sites before reactivation promotes the destabilization of resistant memories such as those of stressed animals. We tested the influence of pre-reactivation D-cycloserine (DCS), a partial NMDA agonist, on MDZ's effect on fear memory reconsolidation in stressed animals. Our findings indicate that DCS before reactivation promotes retrieval-induced lability in resistant memory traces, as MDZ-induced memory impairment in stressed rats became evident with pre-reactivation DCS but not after pre-reactivation sterile isotonic saline.

Neuropsychopharmacology (2010) 35, 1097-I I08; doi:I0.1038/npp.2009.2 I5; published online 30 December 2009

Keywords: reactivation-reconsolidation; fear memory; stress; midazolam; D-cyloserine

\section{INTRODUCTION}

A number of studies have revealed that stressful experiences can affect cognitive functions, including those related to emotional learning and memory (Payne et al, 2007; Roozendaal, 2002; Roozendaal et al, 2009). Although these effects are dependent on a number of factors (Bisaz et al, 2008), numerous studies have revealed a facilitating role of stress, and of hormones functionally associated with stressful experiences on the consolidation of aversive memory (Cordero et al, 2003; McGaugh, 2002; Rodríguez Manzanares et al, 2005; Roozendaal et al, 2008; Shors and

*Correspondence: Dr VA Molina, Departamento de Farmacología, Facultad de Ciencias Químicas, Universidad Nacional de Córdoba, Haya de la Torre y Medina Allende, Ciudad Universitaria, Córdoba 5000, Argentina, Tel: + 51 035। 4334437, Fax: +035। 433 4420,

E-mail:vmolina@fcq.unc.edu.ar

Received 16 July 2009; revised 17 November 2009; accepted 18 November 2009
Mathew, 1998). These results are consistent with the widespread notion that emotionally arousing experiences induce stronger and long-lasting memories than neutral ones (Cahill and McGaugh, 1998; McGaugh, 2004; Sandi, 1998).

The recall of a previously stable consolidated memory may render that memory labile under certain boundary conditions. That is, after retrieval the memory trace becomes susceptible to interference by pharmacological agents, including benzodiazepines' ligands, within a limited time window (Bustos et al, 2006). After this labile phase, memories undergo a restabilization process dependent on new protein synthesis usually referred to as reconsolidation (Alberini, 2005; Dudai, 2006; Nader et al, 2000; Sara, 2000). This process has been reported in a wide number of species (Anokhin et al, 2002; Pedreira and Maldonado, 2003; Sangha et al, 2003; Suzuki et al, 2004), including humans (Forcato et al, 2007; Walker et al, 2003), and evidenced in a variety of memory paradigms involving either aversive or appetitive stimuli (Dudai and Eisenberg, 2004; Lee et al, 2005). 
The emergence of retrieval-induced lability and the subsequent development of the protein-dependent reconsolidation process are closely associated with the protocol of memory reactivation (Riccio et al, 2007). Moreover, there are boundary conditions that place constraints on the onset of both the labile phase and the re-stabilization process (Tronson and Taylor, 2007). For instance, memory age, the duration of the reactivation period, and the interaction between these two factors have a decisive influence on the susceptibility to disruption after memory reactivation (Bustos et al, 2009; Suzuki et al, 2004). As memory ages, it is more difficult to induce post-retrieval retrograde amnesia by pharmacological intervention as compared with newer memories (Frankland et al, 2006; Milekic and Alberini, 2002; Suzuki et al, 2004). Regarding the duration of the reactivation session, a brief one results in reconsolidation, whereas a prolonged or repeated reactivation sessions induces extinction of the consolidated memory (Tronson and Taylor, 2007). Interestingly, a slight increase in the duration of the reactivation session promotes the vulnerability of remote memories to drug-induced interference (Bustos et al, 2009; Suzuki et al, 2004).

The behavioral sequelae of stressful experiences including those exerted on the emergence of aversively motivated memory are closely linked to reduced central GABAergic neurotransmission. In line with this argument, it has been proposed that the decrease in the inhibitory GABAergic control has a major role in the promoting effect of stress on both formation of fear memory and induction of long-term potentiation (LTP) in the basolateral amygdala complex (BLA) (Rodríguez Manzanares et al, 2005). Moreover, not only allosteric modulators of GABA-A receptors such as benzodiazepine (BDZ) agents (positive modulators) but also the inverse agonist (negative modulators) of $\mathrm{BDZ}$ sites have a decisive influence on learning and memory processes (Bovet et al, 1966; Brioni and McGaugh, 1988; Brioni et al, 1993; Castellano and McGaugh, 1989; Castellano et al, 1989; Chapouthier and Venault, 2002; Izquierdo et al, 1990; Jasnow and Huhman, 2001; Luft et al, 2004). Accordingly, a robust interference of fear memory reconsolidation was reported after midazolam (MDZ), a short acting BDZ ligand, administered briefly after reactivation (Bustos et al, 2006, 2009). Benzodiazepines are universally used for the clinical management of diverse fear and anxiety disorders mostly associated with traumatic memories. One of the aims of this study was to assess MDZ vulnerability after reactivation of recent and remote contextual fear memories in animals that had experienced a stressful situation before learning.

Recent data have showed that the blockade of amygdala NMDA sites interfere with retrieval-induced lability, as the reactivated memory became immune to the disrupting effect of a protein synthesis inhibitor (Ben Mamou et al, 2006). These findings suggest that the activation of NMDA receptors is an essential neurobiological event for the occurrence of the labile phase during memory reactivation. Hence, the current research investigated whether activating NMDA sites before reactivation promotes the destabilization of resistant memories such as those formed in previously stressed. To achieve this goal, we tested the influence of D-cycloserine (DCS), a partial NMDA agonist administered before recall, on MDZ's disruptive effect on fear memory reconsolidation in animals subjected to restraint before fear acquisition.

\section{METHODS AND MATERIALS}

\section{Animals}

Male Wistar rats (weighing between 280 and $320 \mathrm{~g}$ ) from our colony maintained at the Department of Pharmacology of the Facultad de Ciencias Químicas, Universidad Nacional de Córdoba were used. Animals were housed in standard laboratory Plexiglas cages (dimension of the cages: $30 \times 45 \times 18 \mathrm{~cm}$ ) in groups of three per cage. Food and water were available ad libitum. Animals were maintained on a 12-h light/dark cycle (lights on at 0700 hours) and at a room temperature of $21-23^{\circ} \mathrm{C}$. The protocols used were approved by the Animal Care Committee of the Facultad de Ciencias Químicas, Universidad Nacional de Córdoba and are consistent with the standards outlined in the NIH Guide for the Care and Use of Laboratory Animals. The number of animals used, as well as their suffering, was kept to the minimum possible needed to accomplish the goals of this study.

\section{Drugs}

Midazolam (Gobbi Novag S.A., Buenos Aires, Argentina) was diluted in sterile isotonic saline (SAL) $(0.9 \% \mathrm{w} / \mathrm{v})$ to a concentration of $1.0,1.5$, and $3.0 \mathrm{mg} / \mathrm{ml}$ and administered intraperitoneally (i.p.). The total volume of drug or an equivalent amount of SAL was $1.0 \mathrm{ml} / \mathrm{kg}$ in all cases.

D-Cycloserine (Sigma, Poole, UK) was dissolved in saline for i.p. injection $(1 \mathrm{ml} / \mathrm{kg})$. The dose of DCS selected $(15 \mathrm{mg} / \mathrm{kg})$ was reported to facilitate extinction of fear memory (Bertotto et al, 2006; Ledgerwood et al, 2003; Walker et al, 2002).

\section{Stressor}

Rats were transferred in their home cages to an experimental room and placed in a plastic restrainer (fitted closely to the body size with only the tail and the tip of the nose free (Cancela et al, 1988). At the end of the stress session, rats were returned to the colony room. Control animals were transferred to the experimental room, gently handled and then returned to the colony room.

\section{Conditioning Apparatus}

The conditioning environment was designated as context $\mathrm{A}$ (A). It was made of gray plastic $(20 \times 23 \times 20 \mathrm{~cm})$ with a clear lid and the floor consisted of 10 parallel stainless steel grid bars, each measuring $4 \mathrm{~mm}$ in diameter and spaced $1.5 \mathrm{~cm}$ a part (center to center), enclosed within a sound attenuating chamber. The grid floor was attached to a scrambled shocker (Ugo Basile Biological Research Apparatus, Italy) to provide footshock. Background noise was provided by ventilation fans and shock scramblers $(55 \mathrm{~dB})$. The illumination was provided by a $2.5 \mathrm{~W}$ white light bulb.

A second distinctive environment designated as context $B$ (B) was made as different as possible from A, and located in 
a different room. The novel context was made of wood and had a transparent plastic lid, black walls and black rubber floor, dimensions being $33 \times 25 \times 33 \mathrm{~cm}$. The chamber was brightly illuminated by three lights.

Experiments were always performed between 1100 and $1400 \mathrm{~h}$ with the experimenters unaware of the treatment condition.

\section{Behavioral Procedure}

Rats were habituated to handling and injected with SAL for at least 2 days before the start of each experiment. Each experiment consisted of four phases: stress session, conditioning, re-exposure (reactivation session), and testing session. An acoustically isolated room was used to run the training and the other phases (re-exposure and test) of the experiment.

Stressor session. On day 1, rats were placed for $30 \mathrm{~min}$ in the plastic restrainer. This procedure was selected on the basis of earlier findings from our laboratory using a similar stress protocol to that performed in this study (Martijena et al, 1997, 2002; Rodríguez Manzanares et al, 2005; Isoardi et al, 2007). In these studies we showed that stress exposure attenuated the inhibitory GABAergic control in BLA, leading to neuronal hyperexcitability and facilitated induction of LTP in BLA, associated with the enhancement of fear memory. These effects were reversed by local and systemic benzodiazepine administration.

Contextual fear conditioning. On day 2, animals were subjected to the conditioning procedure (Bustos et al, 2006, 2009; Isoardi et al, 2004). Training consisted in placing each rat in the chamber (A) and allowing a 3 min acclimation period (pre-shock period). After this session, rats received three footshocks $(0.25 \mathrm{~mA}, 3 \mathrm{~s}$ duration at antershock interval $30 \mathrm{~s}$; unconditioned stimuli). Animals remained in the chamber for an additional 2 min (post-shock period). At the end of this period, rats were removed and subsequently placed in their home cages.

Re-exposure session. Rats were re-exposed to A without shocks for different periods of time (3 or $5 \mathrm{~min}$ ) 1,7 , or 21 days after training, according to the experiment performed.

Test session. The test was always assessed $24 \mathrm{~h}$ after reexposure to A by re-placing the rats in the training environment for $5 \mathrm{~min}$.

The freezing response of each rat was scored during the 3 min pre-shock period, the 2 min post-shock period, the reactivation trial, and testing session. The total time spent freezing in each period was quantified (in seconds) using a stopwatch and expressed as the percentage of total time (Bustos et al, 2006, 2009). Freezing, a commonly used index of fear in rats (Blanchard and Blanchard, 1969), was defined as a total absence of body and head movement except that associated with breathing.

Additional groups of rats were conditioned and received injections of SAL or MDZ after exposure to $\mathrm{B}$ (no reactivation procedure).
Each experiment was independently conducted with different rats, and with conditions counterbalanced in running time.

The aim of this first series of experiments (Experiments 1-3) was to examine the influence of previous stress on the interplay between the CS re-exposure duration, the age of the memory trace, and the disruptive efficacy of different MDZ doses on memory reconsolidation.

\section{Experiment 1}

This experiment was designed to evaluate the influence of stress on MDZ's disruptive effect on the reconsolidation process of a 1-day fear memory. We investigated the efficacy of different doses of $\mathrm{MDZ}$ post-reactivation to interfere with fear memory reconsolidation in rats subjected to previous stress. On day 1, animals were randomly assigned to two experimental groups NO STRESS (NS) and STRESS (S). The STRESS group was immobilized as described before and NO STRESS rats were returned to their home cages without any further manipulation. On day 2 , both groups were trained as previously described and, $24 \mathrm{~h}$ later, re-exposed to A either for 3 or 5 min (reactivation procedure) and immediately administered (i.p.) either with SAL $(3 \mathrm{~min}$, NS $(n=9), \mathrm{S}(n=7) ; 5 \mathrm{~min}$, NS $(n=10), \mathrm{S}$ $(n=9)) ; \mathrm{MDZ} 1.5 \mathrm{mg} / \mathrm{kg}(3 \mathrm{~min}, \mathrm{NS}(n=7), \mathrm{S}(n=8) ; 5 \mathrm{~min}$, NS $(n=10), \mathrm{S}(n=11))$, or MDZ $3 \mathrm{mg} / \mathrm{kg}(3 \mathrm{~min}, \mathrm{NS}(n=8)$, $\mathrm{S}(n=11) ; 5 \mathrm{~min}$, NS $(n=10), \mathrm{S}(n=11))$. One day later, rats were re-located in A and their freezing scored (test).

To test whether the potential impairment induced by $\mathrm{MDZ}$ is selectively dependent on the reactivation procedure, additional NO STRESS and STRESS groups were trained as previously described except that on day 3 rats were placed in a novel context (B). After exposure to $\mathrm{B}$, animals were injected either with SAL (NS $(n=6), \mathrm{S}(n=7))$ or MDZ $1.5 \mathrm{mg} / \mathrm{kg}$ (NS $(n=8), \mathrm{S}(n=9))$, the test was conducted 1 day later by relocating the rats in A for 5 min. Fear memory was assessed as previously described.

\section{Experiment 2}

This experiment was designed to evaluate the influence of stress on MDZ's disruptive effect on the reconsolidation of a 7-day fear memory. Animals were randomly assigned to two experimental groups (NO STRESS and STRESS) and on days 1 and 2, submitted to the same treatment as described in experiment 1 . Memory was reactivated 7 days later for different periods of time ( 3 or $5 \mathrm{~min}$ ) and rats were either administered with SAL (3 min, NS $(n=10), S(n=7) ; 5 \mathrm{~min}$, NS $(n=10)$, $\mathrm{S}(n=7)) ; \mathrm{MDZ} 1.5 \mathrm{mg} / \mathrm{kg}(3 \mathrm{~min}, \mathrm{NS}(n=8), \mathrm{S}(n=8) ; 5 \mathrm{~min}$, NS $(n=10), \mathrm{S}(n=12))$ or MDZ $3 \mathrm{mg} / \mathrm{kg}(3 \mathrm{~min}$, NS $(n=8)$, $\mathrm{S}(n=9) ; 5 \mathrm{~min}, \mathrm{NS}(n=10), \mathrm{S}(n=12))$ immediately after re-exposure. One day later, rats were relocated in $\mathrm{A}$ and their freezing assessed for a 5-min period.

\section{Experiment 3}

This experiment was designed to investigate the influence of stress on MDZ's disruptive effect on the reconsolidation of a 21-day fear memory. Animals were randomly assigned to two experimental groups (NO STRESS and STRESS) and on days 1 and 2, submitted to the same treatment as described 
in experiment 1 . Memory was reactivated 21 days later and rats were either administered with SAL (NS $(n=10)$, S $(n=8))$ or $\mathrm{MDZ} 1.5 \mathrm{mg} / \mathrm{kg}$ (NS $(n=7), \mathrm{S}(n=9))$ or $\mathrm{MDZ}$ $3 \mathrm{mg} / \mathrm{kg}$ (NS $(n=11), \mathrm{S}(n=9))$ immediately after reexposure. One day later, all rats were re-exposed to $\mathrm{A}$ and their freezing recorded (test).

\section{Experiment 4}

Finally, we investigate the influence of pre-reactivation DCS administration on MDZ's disruptive effect on the reconsolidation of a 7-day fear memory in NO STRESS and STRESS animals. This time point was selected on the basis of the previous findings. A 7-day memory in control unstressed animals is specifically reactivated by re-exposure to the associated context (Biedenkapp and Rudy, 2007; Bustos et al, 2009; Wiltgen and Silva, 2007). Moreover, at this time point, the vulnerability to MDZ's disruptive effect on memory reconsolidation is similar to the one observed in 1-day-old memories (Bustos et al, 2009).

Animals were randomly assigned to two experimental groups (NO STRESS and STRESS) and submitted to the same treatment on days 1 and 2 as described in Experiment 1. Seven days later, $30 \mathrm{~min}$ before a 3 -min reactivation period, rats received either DCS or SAL. Immediately after, rats received SAL (NS-SAL-SAL $(n=12)$, NS-DCS-SAL $(n=11)$, S-SAL-SAL $(n=12)$, S-DCS-SAL $(n=12))$ or MDZ $3 \mathrm{mg} / \mathrm{kg} \quad(\mathrm{NS}-S A L-M D Z \quad(n=14), \quad$ NS-DCS-MDZ $(n=12)$, S-SAL-MDZ $(n=10)$, S-DCS-MDZ $(n=11))$. One day later, rats were re-located in $A$ and their freezing recorded (Test 1 ). Ten days after this testing trial, animals were located again in A and their freezing recorded (Test 2).

\section{Statistical Analysis}

Results were expressed as mean \pm SEM. Significant ANOVAs were followed by post hoc Bonferroni analysis to enable specific groups comparison $(P<0.05$ was regarded as significant).

\section{RESULTS}

\section{Experiment 1}

Previous stress enhanced the resistance of a 1-day memory trace to MDZ's disruptive effect on fear memory reconsolidation. We have demonstrated that the CS reexposure duration and the interval between fear training and re-exposure determines the effectiveness of MDZ to disrupt fear memory reconsolidation (Bustos et al, 2009). In this experiment, we next asked whether previous stress can influence MDZ's ability to disrupt reconsolidation of a recent fear memory.

As depicted in Figure $1 \mathrm{~b}$, during the 3 min reactivation period no difference was found between SAL, MDZ 1.5 and MDZ $3 \mathrm{mg} / \mathrm{kg}$-treated rats between both groups (NO STRESS and STRESS) in their freezing response. In line with Bustos et al (2009), a significant reduction of freezing was found in MDZ-treated rats during the test at both doses (1.5 and $3 \mathrm{mg} / \mathrm{kg}$ ) in NO STRESS group. These findings support the view that MDZ prevents the reconsolidation of a 1-day fear memory. Conversely, previously restrained rats (STRESS group), administered with SAL or MDZ (1.5 and $3 \mathrm{mg} / \mathrm{kg}$ ) after a $3 \mathrm{~min}$ re-exposure, displayed similar levels of freezing at the test. These data reveal that MDZ does not affect reconsolidation under this experimental condition. A stress pre-treatment $($ STRESS, NO STRESS $) \times$ drug treatment (SAL, MDZ 1.5, MDZ 3.0) $\times$ sample (CS re-exposure, test) ANOVA revealed significant main effects for stress pre-treatment $(\mathrm{F}(1,44)=35.792, P<0.01)$, drug treatment $(\mathrm{F}(2,44)=18.485, P<0.01)$, and sample $(\mathrm{F}(1,44)=148.94$, $P<0.01)$, and significant pre-treatment $\times$ treatment $(\mathrm{F}(2,44)=$ $20.178, P<0.01)$, pre-treatment $\times$ sample $(\mathrm{F}(1,44)=74.054$, $P<0.01)$, sample $\times$ treatment $(\mathrm{F}(2,44)=13.029, \quad P<0.01)$ and sample $\times$ pre-treatment $\times$ treatment $(\mathrm{F}(2,44)=12.686$, $P<0.01)$ interactions. The post hoc analysis revealed that only in the NO STRESS group did MDZ-administered rats exhibit significantly less freezing than SAL-administered rats during the test $(P \leqslant 0.004)$.

The reactivation duration is an important constraint of retrieval-induced memory lability. Moreover, the CS
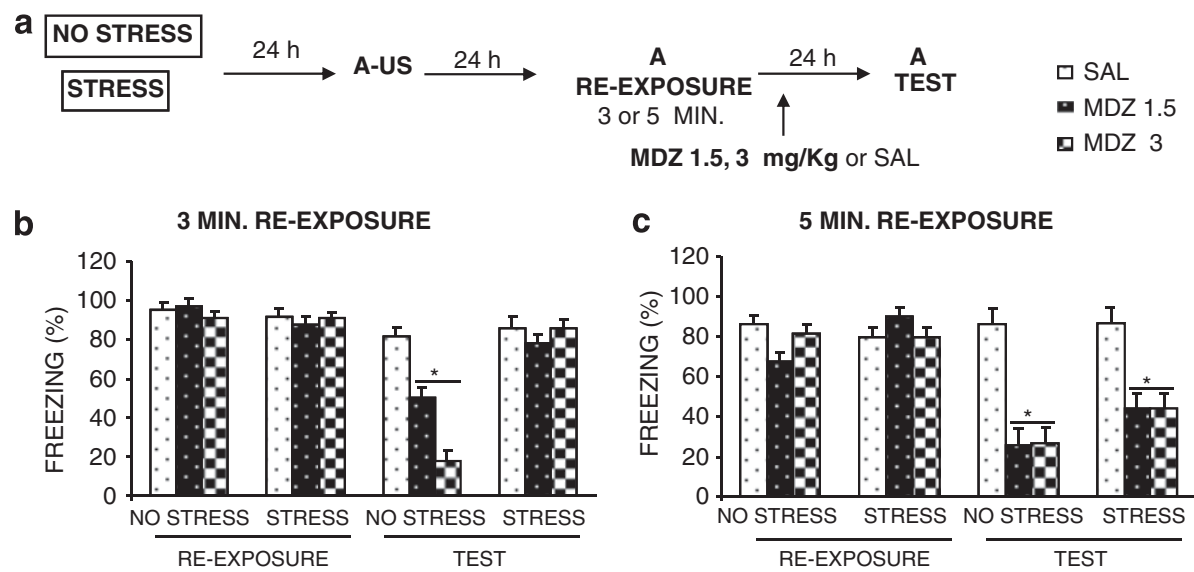

Figure I Influence of earlier stress on the effect of MDZ (I.5 or $3 \mathrm{mg} / \mathrm{kg}$ ) on the reconsolidation of I day fear contextual memory. (a) Experimental design used with data presented below. (b) MDZ 1.5 or $3 \mathrm{mg} / \mathrm{kg}$ administration after a 3 min re-exposure has no effect on the reconsolidation process in STRESS group ( $n=7 / 10$ per group). (c) Reconsolidation after 5 min re-exposure is disrupted by MDZ administration ( 1.5 and $3 \mathrm{mg} / \mathrm{kg}$ ) in both groups (NO STRESS and STRESS) ( $n=9 / 10$ per group). Data are the mean \pm SEM percentage of time spent freezing during re-exposure to $A(3$ or 5 min) and during the test. *Significantly different than SAL group during the test $(P \leqslant 0.02)$. 
re-exposure duration affects the vulnerability of memories of different ages to the disruptive influence of MDZ (Bustos et al, 2009). The effect of MDZ administration on fear memory reconsolidation after a longer reactivation session ( $5 \mathrm{~min}$ ) is shown in Figure 1c. As opposed to the absence of effect observed after a shorter reactivation period, reconsolidation following a longer re-exposure trial ( $5 \mathrm{~min}$ ) became sensitive to MDZ's interfering influence in both groups (NO STRESS and STRESS).

A stress pre-treatment (STRESS, NO STRESS) $\times$ drug treatment (SAL, MDZ 1.5, MDZ 3.0) $\times$ sample (CS reexposure, test) ANOVA revealed significant main effects for drug treatment $(\mathrm{F}(2,55)=16.389, P<0.01)$, and sample $(\mathrm{F}(1,55)=100.12, \quad P<0.01)$, and sample $\times$ pre-treatment $(\mathrm{F}(1,55)=1.6109, P=0.21)$, and sample $\times$ drug treatment $(\mathrm{F}(2,55)=31.036, \quad P<0.01)$ interactions. The post hoc analysis revealed that MDZ-administered rats exhibited significantly less freezing than SAL-administered rats during the test in both groups (STRESS and NO STRESS) $(P \leqslant 0.002)$.

In summary, in STRESS rats, MDZ disrupts contextual fear memory reconsolidation solely when administered after a $5 \mathrm{~min}$ re-exposure session to the associated context while it is ineffective after a $3 \mathrm{~min}$ re-exposure.

Figure $2 \mathrm{~b}$ shows that MDZ $1.5 \mathrm{mg} / \mathrm{kg}$ had no effect on memory when rats were subjected to a $5 \mathrm{~min}$ exposure to $\mathrm{B}$. A stress pre-treatment (STRESS, NO STRESS) $\times$ drug treatment (SAL, MDZ 1.5) $\times$ sample (B-exposure and test) ANOVA revealed significant main effect for stress pre-treatment $(\mathrm{F}(1,26)=16.642, \quad P<0.01)$, and sample $(\mathrm{F}(1,26)=65.157, \quad P<0.01)$, and sample $\times$ pre-treatment
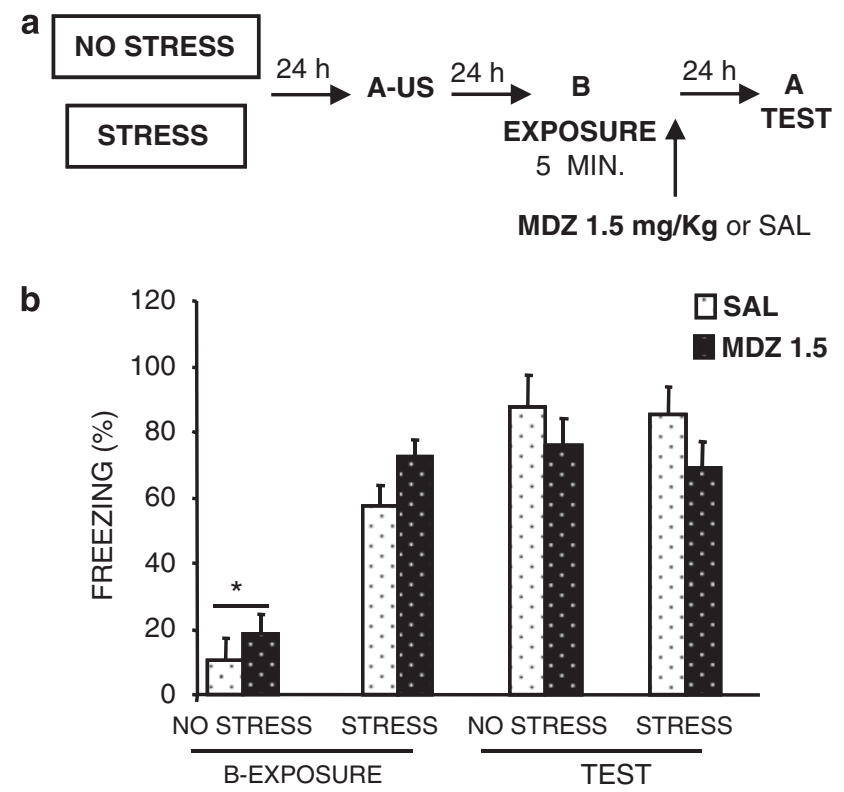

Figure 2 Effect of MDZ $1.5 \mathrm{mg} / \mathrm{kg}$ administration after $5 \mathrm{~min}$ exposure session to $\mathrm{B}$ (NO reactivation-B exposure). (a) Experimental design used with data presented below. (b) MDZ administration after exposure to a novel environment did not affect memory when tested in the associated context (a). Similar levels of freezing were observed between SAL- and MDZ-treated rats $(1.5 \mathrm{mg} / \mathrm{kg})$ in both groups (NO STRESS and STRESS) during the test. Data are the mean \pm SEM percentage of time spent freezing during exposure to $B$ and during the test ( $n=6 / 9$ per group). *Significantly different than the rest of the groups during exposure to $B$ and during the test $(P<0.01)$. interaction $(\mathrm{F}(1,26)=6.4536, \quad P=0.02)$. The post hoc analysis revealed that when exposed to $B$, the NO STRESS group exhibited significantly less freezing than the STRESS group, but also less freezing than all the groups re-exposed to A during the test $(P \leqslant 0.02)$. During such test, no differences were observed among any of the groups.

Similar levels of freezing between SAL and MDZ-injected STRESS animals were observed during the exposure to the novel context (no reactivation) and during the test.

In short, these findings indicate, first, that re-exposure to the associated environment (reactivation session) is essential for MDZ's disruptive effect on memory reconsolidation.

\section{Experiment 2}

A 7-day memory trace in previously stressed rats remains immune to MDZ post-reactivation administration. As previously shown, MDZ blocks the reconsolidation of a 7-day contextual fear memory when administered after a 3-min reactivation period (Bustos et al, 2009). Therefore, the present experiment tested (a) whether a traumatic event before conditioning influenced retrieval-induced lability of a 7-day fear memory, and (b) whether increasing the CS re-exposure session affected MDZ interference with memory reconsolidation. In this experiment, a similar protocol to that described in Experiment 1 was used but the re-exposure session was performed 7 days after conditioning. Following memory reactivation ( 3 or $5 \mathrm{~min}$ ), rats were injected either with SAL, MDZ $1.5 \mathrm{mg} / \mathrm{kg}$ or $\mathrm{MDZ} 3 \mathrm{mg} / \mathrm{kg}$ and subsequently tested in the associated context. As depicted in Figure $3 b$ and $c$, both groups (STRESS and NO STRESS) showed similar levels of freezing during the re-exposure session. As expected, fear memory was disrupted by both MDZ doses in the NO STRESS group. In contrast, MDZ did not affect the reconsolidation of a 7-day memory in the STRESS group even after a longer reactivation period (5 min). In fact, SAL- and MDZ-treated animals exhibited similar levels of freezing during the test (Figure $3 b$ and $c$ ).

In the $3 \mathrm{~min}$ re-exposure experiment, a stress pretreatment (STRESS, NO STRESS) $\times$ drug treatment $(\mathrm{SAL}$, MDZ 1.5, MDZ 3.0) $\times$ sample (CS re-exposure, test) ANOVA revealed significant main effect for pre-treatment $(\mathrm{F}(1,44)=47.982, \quad P<0.01)$, drug treatment $(\mathrm{F}(2,44)=$ $8.6362, P<0.01)$, and sample $(\mathrm{F}(1.44)=117.59, P<0.01)$, and significant pre-treatment $\times$ drug treatment $(\mathrm{F}(2,44)=$ $7.8623, P<0.01)$, sample $\times$ pre-treatment $(\mathrm{F}(1,44)=70.461$, $P<0.01), \quad$ sample $\times$ drug treatment $\quad(\mathrm{F}(2,44)=6.6416$, $P<0.01)$, and sample $\times$ pre-treatment $\times$ drug treatment $(\mathrm{F}(2,44)=13.808, \quad P<0.01)$ interactions. The post hoc analysis revealed that MDZ-administered rats exhibited significantly less freezing than SAL-administered rats during the test only in the NO STRESS group $(P<0.01)$.

With 5 min re-exposure, a stress pre-treatment (STRESS, NO STRESS) $\times$ drug treatment (SAL, MDZ 1.5, MDZ 3.0) $\times$ sample (CS re-exposure, test) ANOVA revealed significant main effect for pre-treatment $(\mathrm{F}(1,55)=17.725$, $P<0.01)$, drug treatment $(\mathrm{F}(2,55)=11.622, P<0.01)$, and sample $(\mathrm{F}(1.55)=81.307, P<0.01)$, and sample $\times$ pre-treatment $(\mathrm{F}(1,55)=16.833, P<0.01)$, sample $\times$ drug treatment $(\mathrm{F}(2,55)=9.7279, \quad P<0.01)$ interactions. The post hoc analysis revealed that MDZ rats exhibited significantly less 

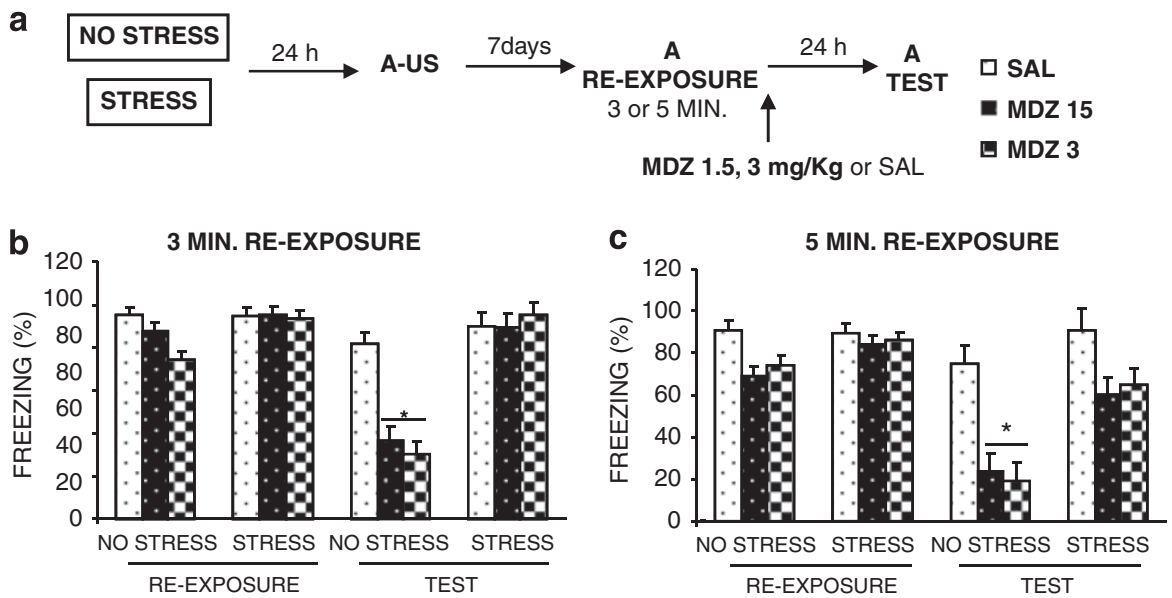

Figure 3 Influence of stress on the effect of MDZ on the reconsolidation of a 7 days fear contextual memory. (a) Experimental design used with data presented below. (b) and (c) MDZ 1.5 or $3 \mathrm{mg} / \mathrm{kg}$ does not affect reconsolidation of a 7-day fear memory regardless of the duration of the re-exposure period (3 or $5 \mathrm{~min}$ ) in previously stressed animals. Data are the mean \pm SEM percentage of time spent freezing during re-exposure to A (3 or 5 min) and during the test ( $n=7 / 12$ per group). *Significantly different than SAL group during the test $(P<0.01)$.

freezing than SAL-administered rats during the test only in the NO STRESS group, $(P<0.01)$.

In summary, MDZ does not affect reconsolidation of a 7-day fear memory in STRESS animals, regardless of the duration of the re-exposure period and the MDZ doses used.

\section{Experiment 3}

Previous stress prevents MDZ's disruptive effect on memory reconsolidation of a 21-day fear contextual memory. Both groups (STRESS and NO STRESS) showed similar levels of freezing during the re-exposure session (Figure 4b), whereas the fear behavior of NO STRESS rats was reduced after both doses of MDZ during the test. In contrast, MDZ did not affect the freezing behavior of a 21-day memory in the STRESS group (Figure $4 \mathrm{~b}$ ).

Statistically, a stress pre-treatment (STRESS, NO STRESS) $\times$ drug treatment (SAL, MDZ 1.5, MDZ 3.0) $\times$ sample (CS re-exposure, test) ANOVA revealed significant main effect for pre-treatment $(\mathrm{F}(1,48)=40.82, P<0.01)$, sample $(\mathrm{F}(1.48)=91.73, \quad P<0.01)$, and drug treatment $(\mathrm{F}(2,48)=19.93, P<0.01)$, and pre-treatment $\times$ drug treatment $(\mathrm{F}(2,48)=12.85, \quad P<0.01)$, sample $\times$ pre-treatment $(\mathrm{F}(1,48)=50.39, \quad P<0.01), \quad$ sample $\times$ drug treatment $(\mathrm{F}(2,48)=12.59, \quad P<0.01)$, and sample $\times$ pre-treatment $\times$ drug treatment $(\mathrm{F}(2,48)=7.70, P<0.01)$ interactions. A post hoc analysis revealed that rats injected with MDZ showed significantly less freezing than SAL-injected ones during the test only in the NO STRESS group $(P<0.01)$.

In conclusion, the reconsolidation of a 21-day fear contextual memory is immune to MDZ's interference effect in STRESS animals.

\section{Experiment 4}

DCS pre-reactivation facilitates retrieval-induced lability in a memory resistant to MDZ's effect on memory reconsolidation. As observed in the previous experiments, older memories from STRESS animals remained immune to the typical MDZ interference on fear memory reconsolida-

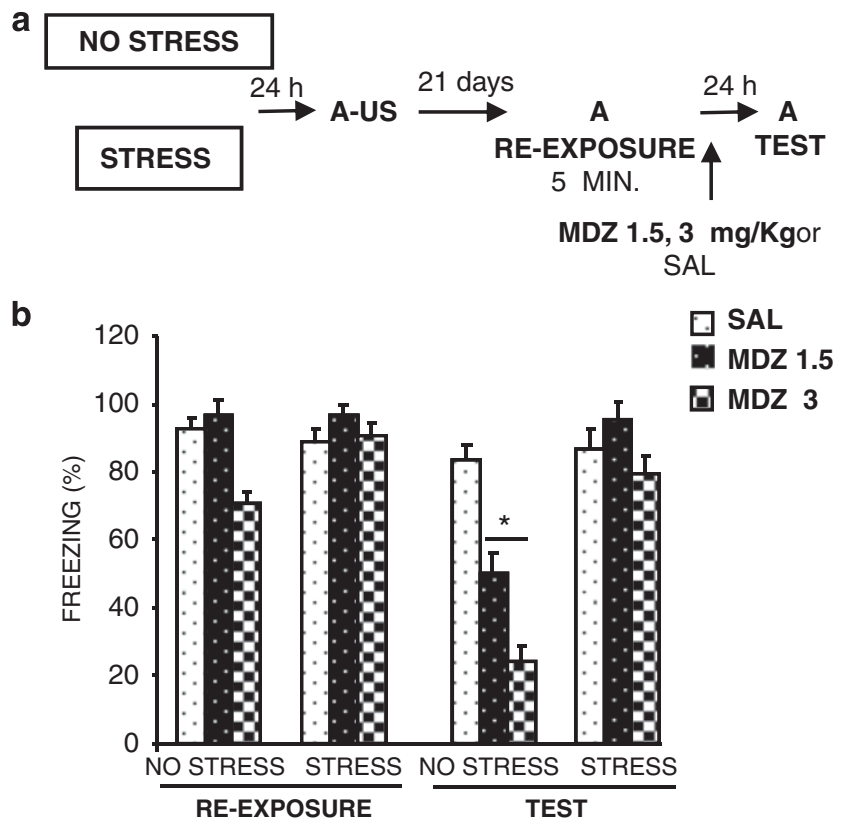

Figure 4 Influence of stress on the effect of MDZ on reconsolidation of a 21 -day fear contextual memory. (a) Experimental design used with data presented below. (b) MDZ 1.5 or $3 \mathrm{mg} / \mathrm{kg}$ administered after $5 \mathrm{~min}$ reexposure does not affect reconsolidation of a 21 -day fear memory in previously stressed animals. Data are the mean \pm SEM percentage of time spent freezing during re-exposure to $A$ and during the test $(n=7 / 10$ per group). *Significantly different than SAL group during the test $(P<0.0 \mathrm{I})$.

tion even after the higher dose and after a longer reactivation period.

The current experiment was designed to facilitate retrieval-induced lability of a memory resistant to interference after MDZ administration. To achieve this goal, we study the influence of DCS, a partial NMDA agonist, administered before the reactivation on the MDZ's effect on memory reconsolidation. 
Comparable levels of freezing were displayed by the different experimental groups during re-exposure, indicating that the pharmacological treatment influenced neither the retrieval process nor the behavioral expression. In the NO STRESS group, the means are as follows: SAL-SAL, $95.76(\mathrm{SD}=2.46)$; SAL-MDZ3, $84.83(\mathrm{SD}=2.27)$; DCS-SAL, $95.58(\mathrm{SD}=2.56)$; $\mathrm{DCS}-\mathrm{MDZ3}, 91.16(\mathrm{SD}=2.13)$. In the STRESS group, the means are as follows: SAL-SAL, 97.98 $(\mathrm{SD}=2.46)$; SAL-MDZ3, $84.85(\mathrm{SD}=2.69)$; DCS-SAL, 94.83 $(\mathrm{SD}=2.46)$; DCS-MDZ3, $90(\mathrm{SD}=2.56)$. The effect of prereactivation DCS administration on subsequent conditioned freezing (tests 1 and 2) is shown in Figure 5b. DCS had no impact when both groups (STRESS - NO STRESS) were administered with SAL. NO STRESS group rats that were treated with SAL or DCS and later on with MDZ $3 \mathrm{mg} / \mathrm{kg}$ displayed the typical interference on memory reconsolidation. As previously observed, STRESS group animals that received SAL before re-exposure followed by post-reactivation MDZ did not show a freezing deficit similar to Experiment 1. STRESS group rats treated first with DCS and later with MDZ $3 \mathrm{mg} / \mathrm{kg}$ exhibited the usual amnesic effect of MDZ on fear memory reconsolidation. Furthermore, persistent low freezing levels were observed in MDZadministered animals that were re-exposed to the training context 10 days after test 1 (test 2). These findings demonstrate the long-lasting interference of MDZ on fear memory reconsolidation in pre-reactivated DCS-administered animals.

A stress pre-treatment (STRESS, NO STRESS) $\times$ drug treatment pre-re-exposure (SAL vs DCS) $\times$ drug treatment post-re-exposure $(\mathrm{SAL}, \mathrm{MDZ} 3.0) \times$ sample $(\mathrm{CS}$ re-exposure, tests 1 and 2) ANOVA revealed sample $\times$ pretreatment $\times$ drug treatment pre-re-exposure $\times$ drug treatment post-re-exposure interaction $(\mathrm{F}(2,180)=4.1406$, $P<0.02)$. A post hoc analysis revealed that rats injected with SAL or DCS pre-re-exposure and then treated with MDZ showed significantly less freezing than rats injected with SAL post-re-exposure during the tests 1 test 2 only in the NO STRESS group $(P<0.01)$. In STRESS rats group, a post hoc analysis showed that only the group pre-treated with DCS and then injected with MDZ showed significantly less freezing than rats pre-treated with DCS and post-reexposure injected with SAL, during the tests 1 and 2 $(P<0.01)$.

All together, these data suggest that DCS pre-reactivation facilitates the occurrence of retrieval-induced lability in a 7-day memory of STRESS rats, thus restoring the susceptibility of fear memory reconsolidation to MDZ disruptive effects.

In order to determine whether the effect of DCS on memory destabilization is selectively dependent on memory reactivation, animals of the STRESS group were immobilized as previously described, and on day 2 both groups (STRESS and NO STRESS) were trained as usual. Seven days later, rats were administered with DCS or SAL 30 min before the exposure to a novel context (B) for $3 \mathrm{~min}$ (Noreactivation procedure). Immediately after this exposure, rats were administered either with SAL (NS-SAL-SAL $(n=8)$, NS-DCS-SAL $(n=9)$, S-SAL-SAL $(n=8)$, S-DCSSAL $(n=8))$ or MDZ $3 \mathrm{mg} / \mathrm{kg}$ (NS-SAL-MDZ $(n=8)$, NSDCS-MDZ $\quad(n=8), \quad$ S-SAL-MDZ $\quad(n=9), \quad$ S-DCS-MDZ $(n=8))$. The following day, all animals were tested in the training context.

DCS administration before exposure to the novel environment together with $\mathrm{MDZ} 3 \mathrm{mg} / \mathrm{kg}$ administration had no effect on fear memory at the test (Figure 6b). A stress pre-treatment (STRESS, NO STRESS $) \times$ drug treatment pre-exposure (SAL vs DCS) $\times$ drug treatment postexposure (SAL, MDZ 3.0) $\times$ sample (B-exposure and test) ANOVA revealed main effects for pre-treatment $(\mathrm{F}(1,58)=50.87, P<0.01)$, and sample $(\mathrm{F}(1,58)=152.13$, $P<0.01)$, and sample $\times$ pre-treatment $\quad(\mathrm{F}(1,58)=54.91$, $P<0.01)$, and sample $\times$ pre-treatment $\times$ drug treatment pre-exposure $(\mathrm{F}(1,58)=8.62, P<0.01)$ interactions. The post hoc analysis revealed that, when exposed to $\mathrm{B}$, the NO STRESS groups exhibited significantly less freezing than the STRESS groups and than the rest of the groups reexposed to A during the test $(P<0.01)$. Similar levels of
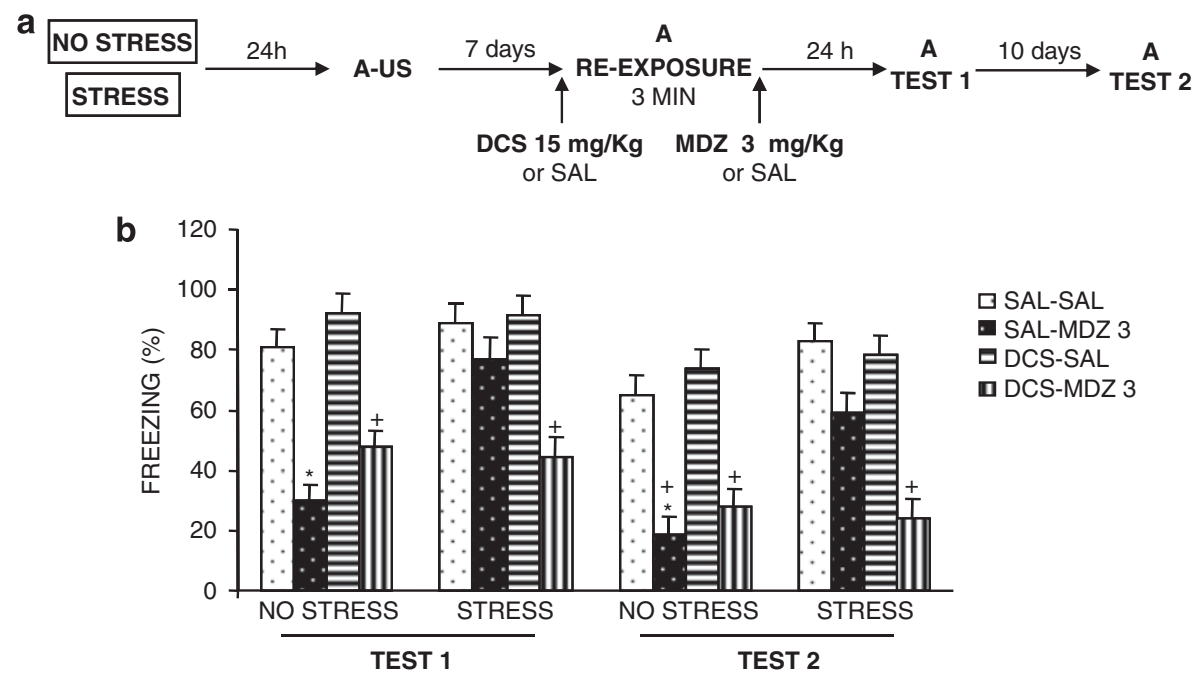

Figure 5 Influence of pre-reactivation DCS administration on MDZ's disruptive effect on reconsolidation of a 7-day-old fear memory in previously stressed animals. (a) The behavioral procedures used in the experiment. (b) DCS pre-reactivation facilitates MDZ's disruptive effect on the reconsolidation of a 7-day contextual fear memory in previously stressed animals. Data are the mean \pm SEM percentage of time spent freezing during tests I and 2 ( $n=I 0 /$ 14 per group). *Significantly different than SAL-SAL group $(P<0.0 \mathrm{I}) .{ }^{+}$Significantly different than DCS-SAL group $(P<0.0 \mathrm{I})$. 

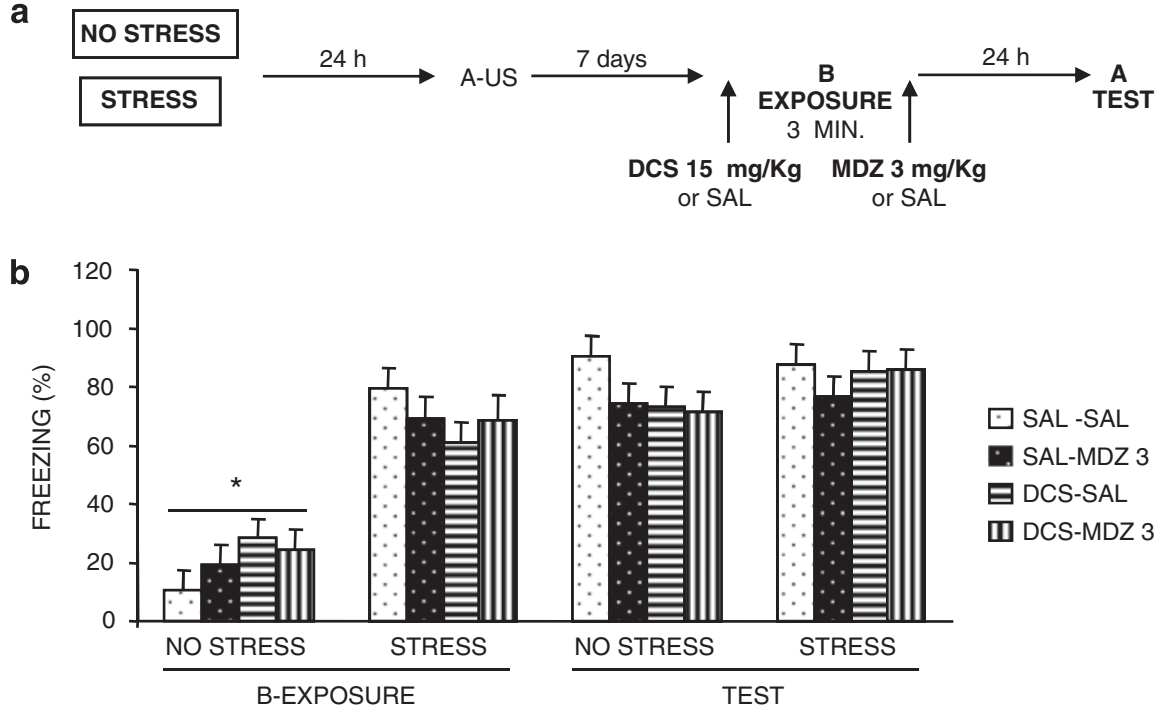

Figure 6 Influence of DCS administration before the exposure to a novel environment (B-no reactivation session) on MDZ's influence on a 7-day fear memory reconsolidation. (a) Experimental design used with data presented below. (b) Neither DCS nor MDZ affects memory reconsolidation during testing. Data are the mean \pm SEM percentage of time spent freezing during exposure to $B(3 \mathrm{~min})$ and during the test (A re-exposure) ( $n=8 / \mathrm{I} 0$ per group). *Significantly different than the rest of the groups during exposure to $B$ and during the test $(P<0.01)$.

freezing during exposure to $\mathrm{B}$ and during the test were observed in the STRESS groups thus indicating that fear memory reconsolidation is not affected by MDZ when administered after the no-reactivation procedure.

These findings indicate that DCS only facilitates the occurrence of retrieval-induced lability in a 7-day memory of STRESS rats when administered before re-exposure to the associated environment (reactivation session).

\section{DISCUSSION}

As expected (Bustos et al, 2006, 2009; Zhang and Cranney, 2008), freezing during testing in unstressed animals revealed the typical reconsolidation impairment induced by MDZ when administered immediately after a brief reactivation of a recent memory. In contrast, MDZ's disruptive effect was absent in stressed rats when administered after a brief reactivation period $(3 \mathrm{~min})$. However, increasing the CS re-exposure duration in a recent trace (1 day memory) favours the onset of the labile phase, as MDZ interfered with memory reconsolidation in stressed animals when the reactivation was prolonged to a 5-min session. Hence, and as previously stated (Bustos et al, 2009; Suzuki et al, 2004), enhancing the reactivation duration favours the destabilization of established consolidated fear memories.

Interestingly, stressed animals exposed to a different context (context B-NO reactivation procedure) exhibited a significant increase in their freezing response, thus suggesting the emergence of a generalization phenomenon. Alternatively, earlier exposure to the restraint and shock experiences may result in a higher unconditioned freezing response when rats are subsequently exposed to an illuminated and novel context (context B). In support of this view, a number of studies have shown that previous stressful stimuli lead to exaggerated fear when stressed animals are faced with novel stimuli that would normally induce minimal emotional disturbances (Adamec et al, 2005; Bignante et al, 2008; Martijena et al, 1997, 2002). In fact, MDZ administration after exposure to the nonassociated context does not affect the established fear memory, as a robust freezing behavior was still evident when MDZ-administered animals were subsequently tested in the associated environment. Thus, the selectivity of this treatment targeting memory reconsolidation is evidenced by the fact that there is no effect on memory reconsolidation when the pharmacological intervention is applied in the absence of the reactivation procedure (exposure to a different context). The generalization phenomenon to other context outside the conditioning environment has been previously reported in animals previously trained with high-intensity footshocks (Baldi et al, 2004). Therefore, it seems appropriate to suggest that increasing the fear status due to earlier aversive experience or by increasing footshock intensity during training promotes the onset of the generalization phenomenon or of an excessive unconditioned freezing response to novel stimuli.

We have previously reported that the vulnerability to MDZ gradually decreases with age and is fully evident in a 36-day memory (Bustos et al, 2009). A number of reports have demonstrated that as the time interval between training and reactivation increases, the trace memory becomes gradually insensitive to diverse pharmacological procedures (Bustos et al, 2009; Milekic and Alberini, 2002; Suzuki et al, 2004). According to the present findings, this phenomenon is clearly potentiated in animals that have experienced a stressful event. In fact, MDZ did not significantly affect memory reconsolidation of older memories (7- and 21-memory age) in stressed animals, even following the higher MDZ dose and after the longer reactivation session ( $5 \mathrm{~min}$ ), whereas it was clearly effective in blocking reconsolidation at the same memory ages in unstressed animals. These data strongly suggest that the experience of a traumatic event before fear acquisition 
strengthens fear memory formation and attenuates the degree of memory instability after retrieval (which becomes more evident in older memories). In support of the view that stronger memories are less vulnerable to disruption after recall, several authors showed that the increase in the number of footshock trials during fear acquisition produces a memory trace that is more resistant to interference after reactivation (Suzuki et al, 2004; Taubenfeld et al, 2009; Wang et al, 2009). It is widely accepted that several conditions constrain the occurrence of reactivation-induced instability and the subsequent development of memory reconsolidation. For instance, memory age and the length of the reactivation trial, as well as the interaction between both factors, have a major role in determining the degree of destabilization after the reactivation of a consolidated memory trace (Alberini et al, 2006; Bustos et al, 2009; Suzuki et al, 2004). Collectively, the present data provide evidence that experiencing a pre-reactivation stress episode, completely unrelated to the cognitive task, makes the memory immune to MDZ's interference. Likewise, the interaction of earlier stress with the passing of time results in a memory trace that is even more immune to disruption by MDZ post-reactivation.

There is evidence that earlier experience with aversive events facilitate the formation of new fear memories in classic fear learning paradigms (Cordero et al, 2003; Rodríguez Manzanares et al, 2005; Shors, 2001). Our findings showed comparable amounts of freezing between control and stressed animals during the reactivation session ( 3 or $5 \mathrm{~min}$ ), regardless of memory age. We have reported that the facilitating effect of stress on conditioned freezing was observed on the second $5 \mathrm{~min}$ period of a $10 \mathrm{~min}$ testing session using a similar fear conditioning paradigm and stressor to those used in this study. This indicates that the enhanced fear is likely to be caused by the attenuation of an extinction process rather than an increased fear acquisition (Rodríguez Manzanares et al, 2005; Yamamoto et al, 2008). In fact, resistance to extinction could reflect the strength of the learning process (Myers and Davis, 2002); therefore, it seems possible that the absence of difference in freezing behavior between control and stressed rats during reactivation be the result of the shorter retrieval session used in this study. Alternatively, we cannot definitively exclude that earlier stress facilitates fear behavior during re-exposure, as such an effect may be masked by a ceiling influence. What is more, under the present experimental protocol, baseline levels of fear averaged $70-80 \%$ during reactivation in unstressed rats. Other authors have shown that the exposure to a single-prolonged stress (SPS) protocol resulted in a facilitated contextual fear memory 1 week, but not 1 day after such stressful stimuli (Takahashi et al, 2007; Kohda et al, 2007). Zhang and Cranney (2008) described, using a modified SPS, that MDZ interfered fear memory reconsolidation even in stressed rats. Apparently, this finding is contradictory to the lack of effect on memory reconsolidation of stressed rats after MDZ administration observed in the current research. It is noteworthy that stress experience strengthened fear memory and this influence is revealed by two main effects: (a) enhanced fear retention or fear expression as previously demonstrated using the SPS (Takahashi et al, 2007; Kohda et al, 2007) and/or (b) the impairment of fear extinction or the resistance to extinguish
(Rodríguez Manzanares et al, 2005; Akirav and Maroun, 2007; Yamamoto et al, 2008). In contrast, Zhang and Cranney (2008) found no increase of fear expression and no alteration of extinction rate in the rats subjected to modified SPS, despite increased anxiety as evidenced in an elevated plus-maze test. Thus, it is likely that this modified SPS protocol does not result in a strengthened fear memory.

Amygdaloid NMDA sites' blockade before reactivation causes trace memories to become immune to the typical interference induced by a protein synthesis inhibitor (Ben Mamou et al, 2006); therefore, it should be expected that activation of NMDA sites before reactivation promote the destabilization phase after retrieval. Hence, the logical prediction of this assumption is that the activation of glutamatergic receptors, for instance by DCS administration, would facilitate the vulnerability to MDZ's disruptive action after retrieval in resistant memories such as those formed in stressed animals. It is well documented that DCS, acting at the strychnine-insensitive glycine-recognition site of the NMDA receptor complex, enhances NMDA receptormediated glutamatergic transmission (Rouaud and Billard, 2003).

This study, using DCS before reactivation, tested this prediction. Importantly, our experiments suggest that activating glutamatergic sites by means of DCS promoted the occurrence of destabilization after the retrieval of fear memories of previously stressed rats. In particular, MDZinduced memory impairment in stressed animals became evident in those animals administered with pre-reactivation DCS but not after SAL pre-reactivation. Furthermore, as a low fear response was still evident during a subsequent re-exposure (10 days after test 1), MDZ's disruptive effect in DCS pre-treated animals was long lasting. Although stressed animas displayed high freezing in the non-associated context in a 7-day memory, MDZ's disruptive effect after DCS was not observed in the absence of re-exposure to the associated context, thus indicating that such interference is selectively dependent on memory reactivation. In contrast, DCS pre-reactivation did not influence MDZ-induced interference in control rats, supporting the view that such destabilization is promoted specifically in resistant memories to MDZ's disruptive effect on fear memory reconsolidation, but not on those that are susceptible to MDZinduced impairment. The possibility that such DCS-induced destabilization can be produced in other experimental conditions should be address in future studies.

A growing body of data supports the view that DCS facilitates the formation of extinction memory (Ledgerwood et al, 2003; Walker et al, 2002; Yamamoto et al, 2008); moreover, DCS facilitates learning and memory using a variety of learning paradigms in diverse animal species (Land and Riccio, 1999; Matsuoka and Aigner, 1996; Monahan et al, 1989; Pitkänen et al, 1995; Pussinen et al, 1997; Quartermain et al, 1994; Thompson et al, 1992). Our findings showed that DCS administration did not affect freezing during reactivation under the present treatment protocol as comparable levels of fear were observed between DCS- and SAL-treated animals, regardless whether animals were subjected to a threatening event before learning. Coincidently, Lee et al (2006) reported that DCS, either administered systematically or locally into the amygdala basolateral complex before reactivation, did not modify 
freezing exhibited during reactivation using a brief reexposure session. Moreover, DCS did not influence the expression of fear-potentiated startle when injected before testing (Walker et al, 2002). Collectively, these experimental findings support the argument that DCS injected before reactivation influences neither the retrieval process nor the expression of freezing behavior or fear responses in fearmotivated memory paradigms.

Concerning the reconsolidation process, a recent report has described that DCS before a brief reactivation session, enhances fear memory during subsequent tests performed 1 or 7 days later. On the basis of these findings, Lee et al (2006) suggest that DCS potentiates memory reconsolidation. The present data show that pre-reactivation DCS has no effect on conditioned freezing response during both test sessions. The conditioning protocol used in this study resulted in $80 \%$ of freezing levels; therefore, it seems likely that this high level of freezing could obscure a potential increase of fear behavior during testing in DCS-treated animals. In support of this argument, Lee et al (2006) revealed that DCS-induced potentiation was only evident using a weak training protocol.

The current data suggest that the underlying mechanism to induce retrieval-induced lability seems to be absent in memories formed under stress. Such a mechanism can be potentially restored by pre-reactivation DCS administration. Recently, Wang et al (2009) have proposed that NR2B NMDA receptor subunit was downregulated when strong or resistant memories were induced by an intense footshock training schedule; in which case, fear memory was not made labile as indicated by insensitivity to the disruptive effect of anisomycin after retrieval. It could then be possible to speculate that a highly stressful condition before learning, as that elicited in this study, is likely to result in a similar mechanism preventing retrieval-induced instability.

At this point, the question is by which potential mechanism could DCS be acting to facilitate destabilization after retrieval, and consequently transform a consolidated resistant memory into a labile one during recall.

It has been recently reported that protein degradation by ubiquitin/proteosome underlies destabilization after fear memory reactivation (Lee et al, 2008). Consistently, local infusion of a proteasome inhibitor before reactivation prevents the amnesic effect of anisomycin on memory reconsolidation (Lee et al, 2008) and the updating of new information in a consolidated fear memory (Lee, 2008). What is more, inhibitors of proteasome activity block the enhancing effects of DCS on NMDA receptor-mediated synaptic responses and on DCS-induced fear extinction (Mao et al, 2008) suggesting that DCS effects are partly associated with the activity of the ubiquitin/proteasome system. Therefore, given that this system underlies retrieval-induced lability as previously proposed, the promoting influence of pre-reactivation DCS on memory destabilization in resistant memories might be caused by the activation of this protein degradation mechanism. Further studies are necessary to address such proposal.

Finally, the development and expression of a wide number of neuropsychiatric disorders are closely linked to the emergence of maladaptive memories following traumatic experiences. The psychological process and the neurobiological mechanisms that underlie such association call for further studies. For this reason, experimental research on stress and fear memory is highly relevant to understand these mechanisms. The current results indicate that earlier experience with a traumatic event together with the passing of time significantly affect the degree of destabilization following the retrieval of a contextual fear memory, making such trace immune to memory reconsolidation disruption. Finally, DCS pre-reactivation administration promotes retrieval-induced lability in a resistant memory trace of previously stressed animals without influencing the destabilization phase after reactivation in control unstressed rats. In conclusion, if MDZ could be potentially used as a pharmacological intervention to interfere with traumatic memories, this study highlights the importance of the combined treatment with DCS to favour the effectiveness of MDZ for attenuating the emotional incidence of undesired resistant memory.

\section{ACKNOWLEDGEMENTS}

This work was supported by grants from FONCyT, and CONICET to VAM and from FONCyT to HM. Thanks are extended to Dolores Trebucq for English technical assistance.

\section{DISCLOSURE}

SG Bustos is a fellow of SECyT-UNC, Argentina. M Giachero is a fellow of CONICET. H Maldonado is researcher of CONICET and full professor of the Universidad de Buenos Aires, Argentina. VA Molina is researcher of CONICET and full professor of the Universidad Nacional de Cordoba, Argentina.

\section{REFERENCES}

Adamec RE, Blundell J, Burton P (2005). Neural circuit changes mediating lasting brain and behavioral response to predator stress. Neurosci Biobehav Rev 29: 1225-1241.

Akirav I, Maroun M (2007). The role of the medial prefrontal cortex-amygdala circuit in stress effects on the extinction of fear. Neural Plast 2007: 30873.

Alberini CM (2005). Mechanisms of memory stabilization: are consolidation and reconsolidation similar or distinct processes? Trends Neurosci 28: 51-56.

Alberini CM, Milekic MH, Tronel S (2006). Mechanisms of memory stabilization and de-stabilization. Cell Mol Life Sci 63: 999-1008.

Anokhin KV, Tiunova AA, Rose SP (2002). Reminder effects: reconsolidation or retrieval deficit? Pharmacological dissection with protein synthesis inhibitors following reminder for a passive-avoidance task in young chicks. Eur J Neurosci 15: 1759-1765.

Baldi E, Lorenzini CA, Bucherelli C (2004). Footshock intensity and generalization in contextual and auditory-cued fear conditioning in the rat. Neurobiol Learn Mem 81: 162-166.

Ben Mamou C, Gamache K, Nader K (2006). NMDA receptors are critical for unleashing consolidated auditory fear memories. Nat Neurosci 9: 1237-1239.

Bertotto ME, Bustos SG, Molina VA, Martijena ID (2006). Influence of ethanol withdrawal on fear memory: effect of D-cycloserine. Neuroscience 142: 979-990.

Biedenkapp JC, Rudy JW (2007). Context preexposure prevents forgetting of a contextual fear memory: implication for regional 
changes in brain activation patterns associated with recent and remote memory tests. Learn Mem 14: 200-203.

Bignante EA, Rodriguez Manzanares PA, Mlewski EC, Bertotto ME, Bussolino DF, Paglini G. et al (2008). Involvement of septal Cdk5 in the emergence of excessive anxiety induced by stress. Eur Neuropsychopharmacol 18: 578-588.

Bisaz R, Conboy L, Sandi C (2008). Learning under stress: a role for the neural cell adhesion molecule NCAM. Neurobiol Learn Mem 91: 333-342.

Blanchard RJ, Blanchard DC (1969). Passive and active reactions to fear-eliciting stimuli. J Comp Physiol Psychol 68: 129-135.

Bovet D, Bovet-Nitti F, Oliverio A (1966). Short and long term memory in two inbred strains of mice. Life Sci 5: 415-420.

Brioni JD, McGaugh JL (1988). Post-training administration of GABAergic antagonists enhances retention of aversively motivated tasks. Psychopharmacology (Berl) 96: 505-510.

Brioni JD, O’Neill AB, Kim DJ, Decker MW (1993). Nicotinic receptor agonists exhibit anxiolytic-like effects on the elevated plus-maze test. Eur J Pharmacol 238: 1-8.

Bustos SG, Maldonado H, Molina VA (2006). Midazolam disrupts fear memory reconsolidation. Neuroscience 139: 831-842.

Bustos SG, Maldonado H, Molina VA (2009). Disruptive effect of midazolam on fear memory reconsolidation: decisive influence of reactivation time span and memory age. Neuropsychopharmacology 34: 446-457.

Cahill L, McGaugh JL (1998). Mechanisms of emotional arousal and lasting declarative memory. Trends Neurosci 21: 294-299.

Cancela LM, Volosin M, Molina VA (1988). Chronic stress attenuation of alpha 2-adrenoceptor reactivity is reversed by naltrexone. Pharmacol Biochem Behav 31: 33-35.

Castellano C, Introini-Collison IB, Pavone F, McGaugh JL (1989). Effects of naloxone and naltrexone on memory consolidation in CD1 mice: involvement of GABAergic mechanisms. Pharmacol Biochem Behav 32: 563-567.

Castellano C, McGaugh JL (1989). Retention enhancement with post-training picrotoxin: lack of state dependency. Behav Neural Biol 51: 165-170.

Chapouthier G, Venault P (2002). GABA-A receptor complex and memory processes. Curr Top Med Chem 2: 841-851.

Cordero MI, Venero C, Kruyt ND, Sandi C (2003). Prior exposure to a single stress session facilitates subsequent contextual fear conditioning in rats. Evidence for a role of corticosterone. Horm Behav 44: 338-345.

Dudai Y (2006). Reconsolidation: the advantage of being refocused. Curr Opin Neurobiol 16: 174-178.

Dudai Y, Eisenberg M (2004). Rites of passage of the engram: reconsolidation and the lingering consolidation hypothesis. Neuron 44: 93-100.

Forcato C, Burgos VL, Argibay PF, Molina VA, Pedreira ME, Maldonado H (2007). Reconsolidation of declarative memory in humans. Learn Mem 14: 295-303.

Frankland PW, Ding HK, Takahashi E, Suzuki A, Kida S, Silva AJ (2006). Stability of recent and remote contextual fear memory. Learn Mem 13: 451-457.

Isoardi NA, Bertotto ME, Martijena ID, Molina VA, Carrer HF (2007). Lack of feedback inhibition on rat basolateral amygdala following stress or withdrawal from sedative-hypnotic drugs. Eur J Neurosci 26: 1036-1044.

Isoardi NA, Martijena ID, Carrer HF, Molina VA (2004). Increased fear learning coincides with neuronal dysinhibition and facilitated LTP in the basolateral amygdala following benzodiazepine withdrawal in rats. Neuropsychopharmacol 29: 1852-1864.

Izquierdo I, Da Cunha C, Huang CH, Walz R, Wolfman C, Medina JH (1990). Post-training down-regulation of memory consolidation by a GABA-A mechanism in the amygdala modulated by endogenous benzodiazepines. Behav Neural Biol 54: 105-109.
Jasnow AM, Huhman KL (2001). Activation of GABA(A) receptors in the amygdala blocks the acquisition and expression of conditioned defeat in Syrian hamsters. Brain Res 920: 142-150.

Kohda K, Harada K, Kato K, Hoshino A, Motohashi J, Yamaji T. et al (2007). Glucocorticoid receptor activation is involved in producing abnormal phenotypes of single-prolonged stress rats: a putative post-traumatic stress disorder model. Neuroscience 148: 22-33.

Land C, Riccio DC (1999). D-Cycloserine: effects on long-term retention of a conditioned response and on memory for contextual attributes. Neurobiol Learn Mem 72: 158-168.

Ledgerwood L, Richardson R, Cranney J (2003). Effects of Dcycloserine on extinction of conditioned freezing. Behav Neurosci 117: 341-349.

Lee JL (2008). Memory reconsolidation mediates the strengthening of memories by additional learning. Nat Neurosci 11: 12641266.

Lee JL, Di Ciano P, Thomas KL, Everitt BJ (2005). Disrupting reconsolidation of drug memories reduces cocaine-seeking behavior. Neuron 47: 795-801.

Lee JL, Milton AL, Everitt BJ (2006). Reconsolidation and extinction of conditioned fear: inhibition and potentiation. J Neurosci 26: 10051-10056.

Lee SH, Choi JH, Lee N, Lee HR, Kim JI, Yu NK (2008). Synaptic protein degradation underlies destabilization of retrieved fear memory. Science 319: 1253-1256.

Luft T, Pereira GS, Cammarota M, Izquierdo I (2004). Different time course for the memory facilitating effect of bicuculline in hippocampus, entorhinal cortex, and posterior parietal cortex of rats. Neurobiol Learn Mem 82: 52-56.

Mao SC, Lin HC, Gean PW (2008). Augmentation of fear extinction by D-cycloserine is blocked by proteasome inhibitors. Neuropsychopharmacology 33: 3085-3095.

Martijena ID, Calvo N, Volosin M, Molina VA (1997). Prior exposure to a brief restraint session facilitates the occurrence of fear in response to a conflict situation: behavioral and neurochemical correlates. Brain Res 752: 136-142.

Martijena ID, Rodríguez Manzanares PA, Lacerra C, Molina VA (2002). Gabaergic modulation of the stress response in frontal cortex and amygdala. Synapse 45: 86-94.

Matsuoka N, Aigner TG (1996). D-cycloserine, a partial agonist at the glycine site coupled to $\mathrm{N}$-methyl-D-aspartate receptors, improves visual recognition memory in rhesus monkeys. J Pharmacol Exp Ther 278: 891-897.

McGaugh JL (2002). Memory consolidation and the amygdala: a systems perspective. Trends Neurosci 25: 456.

McGaugh JL (2004). The amygdala modulates the consolidation of memories of emotionally arousing experiences. Annu Rev Neurosci 27: 1-28.

Milekic MH, Alberini CM (2002). Temporally graded requirement for protein synthesis following memory reactivation. Neuron 36: $521-525$.

Monahan JB, Handelmann GE, Hood WF, Cordi AA (1989). $\mathrm{D}$-cycloserine, a positive modulator of the $N$-methyl-D-aspartate receptor, enhances performance of learning tasks in rats. Pharmacol Biochem Behav 34: 649-653.

Myers KM, Davis M (2002). Behavioral and neural analysis of extinction. Neuron 36: 567-584.

Nader K, Schafe GE, Le Doux JE (2000). Fear memories require protein synthesis in the amygdala for reconsolidation after retrieval. Nature 406: 722-726.

Payne JD, Jackson ED, Hoscheidt S, Ryan L, Jacobs WJ, Nadel L (2007). Stress administered prior to encoding impairs neutral but enhances emotional long-term episodic memories. Learn Mem 14: 861-868.

Pedreira ME, Maldonado H (2003). Protein synthesis subserves reconsolidation or extinction depending on reminder duration. Neuron 38: 863-869. 
Pitkänen M, Sirviö J, MacDonald E, Niemi S, Ekonsalo T, Riekkinen P (1995). The effects of D-cycloserine and MK-801 on the performance of rats in two spatial learning and memory tasks. Eur Neuropsychopharmacol 5: 457-463.

Pussinen R, Nieminen S, Koivisto E, Haapalinna A, Riekkinen Sr P, Sirvio J (1997). Enhancement of intermediate-term memory by an alpha-1 agonist or a partial agonist at the glycine site of the NMDA receptor. Neurobiol Learn Mem 67: 69-74.

Quartermain D, Mower J, Rafferty MF, Herting RL, Lanthorn TH (1994). Acute but not chronic activation of the NMDA-coupled glycine receptor with $\mathrm{D}$-cycloserine facilitates learning and retention. Eur J Pharmacol 257: 7-12.

Riccio CA, Garland BH, Cohen MJ (2007). Relations between the Test of Variables of Attention (TOVA) and the Children's Memory Scale (CMS). J Atten Disord 11: 167-171.

Rodríguez Manzanares PA, Isoardi NA, Carrer HF, Molina VA (2005). Previous stress facilitates fear memory, attenuates GABAergic inhibition, and increases synaptic plasticity in the rat basolateral amygdala. J Neurosci 25: 8725-8734.

Roozendaal B (2002). Stress and memory: opposing effects of glucocorticoids on memory consolidation and memory retrieval. Neurobiol Learn Mem 78: 578-595.

Roozendaal B, McEwen BS, Chattarji S (2009). Stress, memory and the amygdala. Nat Rev Neurosci 10: 423-433.

Roozendaal B, Schelling G, McGaugh JL (2008). Corticotropinreleasing factor in the basolateral amygdala enhances memory consolidation via an interaction with the beta-adrenoceptorcAMP pathway: dependence on glucocorticoid receptor activation. J Neurosci 28: 6642-6651.

Rouaud E, Billard JM (2003). D-cycloserine facilitates synaptic plasticity but impairs glutamatergic neurotransmission in rat hippocampal slices. Br J Pharmacol 140: 1051-1056.

Sandi C (1998). The role and mechanisms of action of glucocorticoid involvement in memory storage. Neural Plast 6: 41-52.

Sangha S, Scheibenstock A, Lukowiak K (2003). Reconsolidation of a long-term memory in lymnaea requires new protein and RNA synthesis and the soma of right pedal dorsal 1. J Neurosci 23: 8034-8040.

Sara SJ (2000). Retrieval and reconsolidation: toward a neurobiology of remembering. Learn Mem 7: 73-84.
Shors TJ (2001). Acute stress rapidly and persistently enhances memory formation in the male rat. Neurobiol Learn Mem 75: 10-29.

Shors TJ, Mathew PR (1998). NMDA receptor antagonism in the lateral/basolateral but not central nucleus of the amygdala prevents the induction of facilitated learning in response to stress. Learn Mem 5: 220-230.

Suzuki A, Josselyn SA, Frankland PW, Masushige S, Silva AJ, Kida $S$ (2004). Memory reconsolidation and extinction have distinct temporal and biochemical signatures. J Neurosci 24: 4787-4795.

Takahashi T, Morinobu S, Iwamoto Y, Yamawaki S (2007). Effect of paroxetine on enhanced contextual fear induced by single prolonged stress in rats. Psychopharmacology (Berl) 189: 165-173.

Taubenfeld SM, Riceberg JS, New AS, Alberini CM (2009). Preclinical assessment for selectively disrupting a traumatic memory via postretrieval inhibition of glucocorticoid receptors. Biol Psychiatry 65: 249-257.

Thompson LT, Moskal JR, Disterhoft JF (1992). Hippocampusdependent learning facilitated by a monoclonal antibody or Dcycloserine. Nature 359: 638-641.

Tronson NC, Taylor JR (2007). Molecular mechanisms of memory reconsolidation. Nat Rev Neurosci 8: 262-275.

Walker DL, Ressler KJ, Lu KT, Davis M (2002). Facilitation of conditioned fear extinction by systemic administration or intraamygdala infusions of D-cycloserine as assessed with fearpotentiated startle in rats. J Neurosci 22: 2343-2351.

Walker MP, Brakefield T, Hobson JA, Stickgold R (2003). Dissociable stages of human memory consolidation and reconsolidation. Nature 425: 616-620.

Wang SH, de Oliveira Alvares L, Nader K (2009). Cellular and systems mechanisms of memory strength as a constraint on auditory fear reconsolidation. Nat Neurosci 12: 905-912.

Wiltgen BJ, Silva AJ (2007). Memory for context becomes less specific with time. Learn Mem 14: 313-317.

Yamamoto S, Morinobu S, Fuchikami M, Kurata A, Kozuru T, Yamawaki S (2008). Effects of single prolonged stress and Dcycloserine on contextual fear extinction and hippocampal NMDA receptor expression in a rat model of PTSD. Neuropsychopharmacology 33: 2108-2116.

Zhang S, Cranney J (2008). The role of GABA and anxiety in the reconsolidation of conditioned fear. Behav Neurosci 122: 1295-1305. 